Article

\title{
Chemical Composition of Two Different Lavender Essential Oils and Their Effect on Facial Skin Microbiota
}

\author{
Marietta Białoń ${ }^{1, * \mathbb{C}}$, Teresa Krzyśko-Łupicka ${ }^{2}$, Ewa Nowakowska-Bogdan ${ }^{3}$ \\ and Piotr P. Wieczorek ${ }^{1}$ \\ 1 Faculty of Chemistry, University of Opole, Oleska 48, 45-052 Opole, Poland \\ 2 Independent Department of Biotechnology and Molecular Biology, Faculty of Natural and Technical Science, \\ University of Opole, Kominka 6A, 45-035 Opole, Poland \\ 3 The Institute of Heavy Organic Synthesis "Blachownia”, Energetyków 9, 47-225 Kędzierzyn-Koźle, Poland \\ * Correspondence: Marietta.Bialon@uni.opole.pl
}

Academic Editor: Francesca Mancianti

Received: 23 July 2019; Accepted: 5 September 2019; Published: 8 September 2019

check for updates

\begin{abstract}
Lavender oil is one of the most valuable aromatherapy oils, its anti-bacterial and anti-fungal activities can be explained by main components such as linalool, linalyl acetate, lavandulol, geraniol, or eucalyptol. The aim of the study was to assess the anti-microbial effects of two different lavender oils on a mixed microbiota from facial skin. The commercial lavender oil and essential lavender oil from the Crimean Peninsula, whose chemical composition and activity are yet to be published, were used. Both oils were analysed by gas chromatography coupled to mass spectrometry. The composition and properties of studied oils were significantly different. The commercial ETJA lavender oil contained $10 \%$ more linalool and linalyl acetate than the Crimean lavender oil. Both oils also had different effects on the mixed facial skin microbiota. The Gram-positive bacilli were more sensitive to ETJA lavender oil, and Gram-negative bacilli were more sensitive to Crimean lavender oil. However, neither of the tested oils inhibited the growth of Gram-positive cocci. The tested lavender oils decreased the cell number of the mixed microbiota from facial skin, but ETJA oil showed higher efficiency, probably because it contains higher concentrations of monoterpenoids and monoterpenes than Crimean lavender oil does.
\end{abstract}

Keywords: facial skin microbiota; gas chromatography with mass spectrometry; lavender essential oil

\section{Introduction}

The generic name "lavender" dates back to ancient times and derives from the Latin word lavare, which means washing and bathing. According to Romans, not only the aromatic qualities but also antiseptic properties were important [1]. Therefore, lavender oil was used as a panacea even in the case of wounds associated with tissue loss [2].

Today, as a preservative and skin regenerator, it is widely used in the cosmetic industry to produce safe tonics, lotions, creams, shampoos, conditioners, shower gels, and soaps by specialist cosmetic companies, such as Dr. Beta-Pollena Aroma, Farmona Organique, Sanoflore, and Yves Rocher.

Because of the mild climate, adequate sunshine, alkaline soil, and natural wind protection, lavender is naturally present in Mediterranean countries.

Lavender belongs to the Labiatae family, which includes $\sim 30$ species of Lavandula. However, only three species with lavender fragrance are of industrial importance. These are as follows [3]:

1. Narrow-leaved lavender (real, medical) Lavandula officinalis Chaix, syn. L. vera DC, L. angustifolia Mill.;

2. Broad-leaved lavender (spike lavender) Lavandula latifolia Vill. (Syn. L. spica DC); 
3. Lavandin, a hybrid of the two preceding species.

In the cosmetics industry, the most popular essential oils are those derived from these plants. Nevertheless, both their odour and chemical composition are determined by a number of factors: plant species or varieties, climatic conditions, growth method and conditions, harvesting, transport, storage, and oil preparation techniques. Lavender oil obtained from L. angustifolia is the most valuable and the most expensive because its efficiency is two-fold lower than that of spike oil, and four-fold lower than that of lavandin oil [4]. Therefore, lavender oil can be falsified with cheaper oils (lavandin or spike). Sometimes, synthetic products such as linalyl acetate are added [4].

Although the main active ingredients are monoterpenes (linalool, linalyl acetate, lavandulol, geraniol, bornyl acetate, borneol, terpineol, and eucalyptol or lavandulyl acetate), these oils may have different anti-bacterial and anti-fungal effects, depending on their chemical composition $[5,6]$. A high and almost equal content of linalool and linalyl acetate (a ratio above one) is required for good anti-microbial properties of lavender essential oil [5,6]. The high concentration of lavandulol and its acetate is also desirable, giving the oil a rosaceous, sharp floral aroma. Good anti-microbial activity requires that the ratio of the content of the sum of linalyl acetate with linalool to the content of terpinen-4-ol in lavender essential oil is more than 13 [3,4]; moreover, this ratio can help to determine the type of oil and its applicability, as presented in Table 1 [7-9]. On the other hand, high concentrations of ocimene, cineole, camphor, or terpinen-4-ol adversely affect the quality of this oil [3,4]. The chemical composition of different lavender species depends on the geographic region of origin (Tables 1 and 2). On the basis of the presented observations, it is obvious that L. angustifolia, Lavandula stoechas, and Lavandula dentata contain large amounts of eucalyptol and camphor (Tables 1 and 2). It should also be noted that lavender oil from Brazil [10] contains borneol at a concentration of $22.4 \%$, which is much higher than that in other L. angustifolia oils (Table 1). Although L. abrialis oil from France [11] and L. bipinnata from Algeria [12] contain large amounts of camphor, they do not contain eucalyptol (Table 2).

Table 1. The components of lavender oil from Lavandula angustifolia described in the literature.

\begin{tabular}{|c|c|c|c|c|c|c|c|c|c|}
\hline \multirow{3}{*}{ Name } & \multicolumn{9}{|c|}{ Lavandula angustifolia-Place and Area (\%) } \\
\hline & \multicolumn{3}{|c|}{ Italy } & \multicolumn{2}{|c|}{ Australia } & \multirow[t]{2}{*}{ China } & \multirow{2}{*}{$\begin{array}{c}\text { Greece } \\
\text { (a) }\end{array}$} & \multirow[t]{2}{*}{ Brazil } & \multirow[t]{2}{*}{ Iran } \\
\hline & (a) & (b) & (c) & (a) & (b) & & & & \\
\hline tricyclene & & & - & $0.02-0.04$ & - & - & - & - & - \\
\hline$\alpha$-thujene & 0.13 & 0.11 & 0.05 & $0.02-0.17$ & - & - & - & - & - \\
\hline$\alpha$-pinene & 0.51 & 0.93 & 0.26 & $0.08-0.73$ & - & - & - & 0.70 & 1.41 \\
\hline camphene & 0.26 & 0.59 & 0.19 & $0.02-0.54$ & 0.19 & 3.98 & - & 0.50 & - \\
\hline$\beta$-phellandrene & - & - & - & $0.02-0.11$ & - & - & - & 3.40 & - \\
\hline$\beta$-pinene & 0.14 & 0.30 & 1.58 & $0.03-1.21$ & - & - & - & 1.10 & 1.52 \\
\hline octen-3-ol & 0.22 & 0.20 & 0.16 & $0.03-1.14$ & 0.28 & 0.35 & - & - & - \\
\hline 3-octanone & 0.36 & 0.68 & - & $0.33-3.49$ & - & - & - & - & - \\
\hline myrcene & 0.12 & - & trace & $0.26-1.22$ & 0.56 & 0.87 & - & 0.70 & 1.02 \\
\hline 3-carene & - & - & - & $0.05-0.30$ & - & 0.45 & - & 0.90 & 0.76 \\
\hline sabinene & 0.31 & 0.75 & 0.31 & $0.04-0.39$ & - & - & - & - & - \\
\hline$p$-cymene & 0.29 & 0.20 & - & $0.10-0.45$ & - & - & - & - & - \\
\hline o-cymene & 0.04 & 0.09 & 0.30 & $0.03-0.12$ & - & - & - & - & - \\
\hline limonene & 1.10 & 2.36 & - & $0.18-3.92$ & 0.24 & 0.19 & - & - & - \\
\hline eucalyptol & 3.98 & 10.89 & 6.75 & $0.1-10.87$ & 1.51 & 2.30 & 4.80 & 7.90 & 3.93 \\
\hline$(E)$ - $\beta$-ocimene & 1.24 & 0.42 & 0.56 & $0.34-2.36$ & 0.09 & 0.52 & - & - & - \\
\hline (Z)- $\beta$-ocimene & 1.02 & 1.32 & 0.77 & $0.95-6.17$ & 0.44 & & - & - & - \\
\hline trans-linalool oxide & - & 0.07 & 1.57 & $0.26-0.99$ & - & - & - & - & - \\
\hline cis-linalool oxide & 0.09 & 0.07 & 1.48 & $0.34-1.09$ & 0.24 & - & - & - & 1.67 \\
\hline trans-sabinene hydrate & 0.39 & 0.34 & - & $0.04-0.20$ & - & - & - & - & - \\
\hline linalool & 35.96 & 36.51 & 35.31 & $23.03-57.48$ & 52.59 & 44.54 & 44.50 & - & 4.91 \\
\hline cis- $p$-menth-2-en-1-ol & - & - & - & $0.02-0.04$ & - & - & - & - & - \\
\hline trans-pinocarveol & 0.18 & 0.10 & - & $0.01-0.34$ & - & - & - & - & - \\
\hline camphor & 5.56 & 11.76 & 7.81 & $0.09-7.10$ & 8.79 & - & - & 3.50 & 2.83 \\
\hline myrtenol & - & - & - & $0.04-0.21$ & - & - & - & 0.40 & - \\
\hline
\end{tabular}


Table 1. Cont.

\begin{tabular}{|c|c|c|c|c|c|c|c|c|c|}
\hline \multirow{3}{*}{ Name } & \multicolumn{9}{|c|}{ Lavandula angustifolia-Place and Area (\%) } \\
\hline & \multicolumn{3}{|c|}{ Italy } & \multicolumn{2}{|c|}{ Australia } & \multirow[t]{2}{*}{ China } & \multirow{2}{*}{$\begin{array}{c}\text { Greece } \\
\text { (a) }\end{array}$} & \multirow[t]{2}{*}{ Brazil } & \multirow[t]{2}{*}{ Iran } \\
\hline & (a) & (b) & (c) & (a) & (b) & & & & \\
\hline borneol & 2.71 & 4.21 & 2.98 & $0.30-4.04$ & 7.50 & 2.45 & 3.90 & 22.40 & 8.57 \\
\hline p-cymen-8-ol & 0.33 & 0.55 & - & $0.12-0.27$ & - & - & - & - & - \\
\hline lavendulol & 0.05 & 0.05 & 0.55 & $0.05-0.86$ & - & - & - & - & - \\
\hline terpinen-4-ol & 6.57 & 2.10 & 3.34 & $0.11-8.07$ & 2.45 & - & 6.90 & 0.90 & - \\
\hline sabine ketone & - & - & - & $0.02-0.10$ & - & - & - & - & - \\
\hline m-cymen-8-ol & 0.03 & 0.09 & - & $0.02-0.18$ & - & - & - & - & - \\
\hline$\alpha$-terpineol & 0.06 & 0.07 & 4.39 & $0.12-6.02$ & 3.03 & 6.75 & 3.50 & 1.20 & 1.98 \\
\hline hexyl butyrate & - & - & 0.43 & $0.12-1.72$ & - & - & - & - & - \\
\hline isobornyl formate & 0.06 & 0.10 & - & $0.10-0.52$ & - & - & - & - & - \\
\hline geraniol & - & - & 0.67 & - & - & 11.02 & - & - & 1.24 \\
\hline cumin aldehyde & - & - & - & $0.04-0.53$ & 0.16 & - & - & - & - \\
\hline carvone & - & - & - & $0.02-0.19$ & - & - & - & 0.40 & - \\
\hline linalyl acetate & 21.74 & 14.42 & 12.09 & $4.01-35.39$ & 9.27 & - & 32.70 & - & - \\
\hline$\alpha$-bisabolol & 1.12 & 0.89 & 3.76 & $0.02-0.71$ & 0.78 & - & - & 13.10 & 2.32 \\
\hline dihydrocarveol & - & - & - & $0.03-0.51$ & - & - & - & - & - \\
\hline bornyl acetate & - & - & - & $0.03-0.32$ & 1.11 & - & - & - & 1.67 \\
\hline lavendulyl acetate & - & - & - & $0.70-6.16$ & 1.32 & 10.78 & - & - & - \\
\hline neryl acetate & 0.06 & - & 1.31 & $0.07-1.23$ & 1.21 & - & - & - & 2.16 \\
\hline$\beta$-bourbonene & 0.17 & 0.09 & - & $0.02-0.09$ & - & - & - & - & - \\
\hline$\alpha$-trans-bergamotene & 0.07 & 0.05 & - & $0.02-0.15$ & 0.07 & - & - & - & - \\
\hline$\alpha$-cederene & - & - & - & $0.01-0.09$ & - & - & - & - & - \\
\hline$\beta$-caryophellene & - & - & - & - & - & - & - & 3.20 & 1.60 \\
\hline caryophyllene & 2.87 & 2.42 & 1.30 & $0.45-2.83$ & 1.00 & 0.50 & 0.30 & - & - \\
\hline$\alpha$-santalene & - & - & - & - & 0.05 & - & - & - & - \\
\hline$\alpha$-cis-bergamotene & 0.07 & 0.06 & - & $0.02-0.09$ & - & - & - & - & - \\
\hline$\beta$-farnesene & 4.02 & 1.07 & 1.00 & $0.17-1.69$ & 1.83 & - & - & - & 0.71 \\
\hline germacene D & 0.77 & 1.50 & - & $0.16-0.94$ & 0.37 & - & - & - & - \\
\hline$\beta$-bisabolene & 0.03 & - & - & - & 0.26 & - & - & 0.80 & - \\
\hline$\gamma$-cadinene & 0.26 & 0.39 & - & $0.03-0.39$ & 0.28 & - & - & 2.90 & - \\
\hline caryophyllene oxide & - & - & - & - & 0.22 & - & - & 4.50 & 2.73 \\
\hline spathulenol & 0.06 & 0.31 & - & $0.01-0.06$ & - & - & - & - & - \\
\hline$\gamma$-muurolol & - & - & - & $0.02-0.48$ & - & - & - & - & - \\
\hline$\tau$-cadinol & - & - & - & $0.02-0.42$ & - & - & - & - & 1.85 \\
\hline$\gamma$-terpinene & - & - & - & $0.05-0.22$ & - & - & - & - & - \\
\hline octen-3-yl acetate & - & - & - & $0.19-4.16$ & - & - & - & - & - \\
\hline norborneol acetate & - & - & - & $0.04-0.51$ & - & - & - & - & - \\
\hline
\end{tabular}

Italy (a)—low Friuli-Venezia Giulia (northeast Italy) [7]; Italy (b)—high Friuli-Venezia Giulia (northeast Italy) [7]; Italy (c)—Betulla srl (Italy) [9]; Australia (a)—Australian Botanical Products (Hallam, Australia) [13]; Australia (b) - The Lavender Patch lavender farm, Victoria, Australia [8]; China (a)—Xinjiang, China [14]; Greece (a)—Crete (Greece) [15]; Brazil—Franca, State of Sao Paulo, Brazil [10]; Iran—Astara, north of Iran [16].

Table 2. The components of other lavender oils described in the literature.

\begin{tabular}{|c|c|c|c|c|c|c|c|c|c|}
\hline \multirow{3}{*}{ Name } & \multicolumn{9}{|c|}{ Place and Area $(\%) \pm S D$} \\
\hline & \multirow{2}{*}{$\begin{array}{c}\text { Lavandin } \\
\text { abrialis }\end{array}$} & \multirow{2}{*}{\multicolumn{2}{|c|}{ stoechas }} & \multirow{2}{*}{$\frac{\text { dentata }}{\text { Algeria }}$} & \multicolumn{2}{|c|}{ Lavandula } & \multirow{2}{*}{$\begin{array}{c}\text { canarien-sis } \\
\text { Australia } \\
\text { (c) }\end{array}$} & \multirow{2}{*}{\multicolumn{2}{|c|}{$\begin{array}{c}\text { multifida } \\
\text { Portugal }\end{array}$}} \\
\hline & & & & & bipinnata & gibsoni & & & \\
\hline tricyclene & 0.03 & - & 0.20 & 0.40 & - & - & - & - & - \\
\hline camphene & 0.30 & 1.40 & 1.30 & - & 0.35 & - & - & - & - \\
\hline$\beta$-phellandrene & - & - & 0.10 & - & - & - & - & - & - \\
\hline$\beta$-pinene & 0.30 & - & 1.30 & 0.20 & - & - & trace & - & - \\
\hline octen-3-ol & 0.30 & - & - & - & - & 2.20 & - & 0.60 & 0.50 \\
\hline 3-octanone & 1.00 & - & - & - & - & - & - & 0.40 & 0.30 \\
\hline
\end{tabular}


Table 2. Cont.

\begin{tabular}{|c|c|c|c|c|c|c|c|c|c|}
\hline \multirow{5}{*}{ Name } & \multicolumn{9}{|c|}{ Place and Area $(\%) \pm S D$} \\
\hline & \multirow{4}{*}{$\begin{array}{c}\begin{array}{c}\text { Lavandin } \\
\text { abrialis }\end{array} \\
\text { France }\end{array}$} & \multirow{2}{*}{\multicolumn{2}{|c|}{ stoechas }} & \multirow{4}{*}{$\begin{array}{c}\text { dentata } \\
\text { Algeria }\end{array}$} & \multicolumn{2}{|c|}{ Lavandula } & \multirow{4}{*}{$\begin{array}{c}\text { canarien-sis } \\
\text { Australia } \\
\text { (c) }\end{array}$} & \multirow{3}{*}{\multicolumn{2}{|c|}{$\begin{array}{c}\text { multifida } \\
\text { Portugal }\end{array}$}} \\
\hline & & & & & bipinnata & gibsoni & & & \\
\hline & & & Greece & & India & India & & & \\
\hline & & Turkey & (b) & & (a) & (b) & & (a) & (b) \\
\hline 3-carene & 0.02 & - & - & - & 0.37 & 1.52 & - & 0.50 & 0.50 \\
\hline sabinene & 0.10 & - & - & 1.40 & 0.39 & - & - & - & - \\
\hline$p$-cymene & 0.04 & - & 4.90 & - & - & 0.82 & trace & 0.30 & 0.20 \\
\hline o-cymene & - & - & - & - & - & - & - & - & - \\
\hline limonene & 0.70 & - & - & - & - & 2.30 & trace & 0.60 & 0.30 \\
\hline eucalyptol & - & 8.03 & 16.30 & 38.40 & - & - & - & - & - \\
\hline$(E)$ - $\beta$-ocimene & 2.60 & - & trace & 0.10 & - & trace & trace & 27.40 & 27.00 \\
\hline (Z)- $\beta$-ocimene & 3.00 & - & - & - & - & 0.30 & 0.60 & 1.70 & 1.50 \\
\hline trans-linalool oxide & 0.20 & - & - & - & - & - & - & - & - \\
\hline$\beta$-citral & & & & & & - & 0.30 & - & - \\
\hline cis-linalool oxide & 0.1 & - & - & - & - & - & - & - & - \\
\hline trans-sabinene hydrate & - & - & - & 0.10 & - & - & - & - & - \\
\hline linalool & 35.00 & 0.29 & 1.20 & trace & 0.94 & 2.65 & 0.90 & 0.30 & 0.20 \\
\hline cis-p-menth-2-en-1-ol & - & - & - & trace & - & - & - & - & - \\
\hline trans-pinocarveol & - & - & - & - & - & - & - & - & - \\
\hline camphor & 8.90 & 18.18 & 9.90 & 1.60 & 7.09 & - & - & - & - \\
\hline myrtenol & - & - & 1.10 & 1.70 & - & - & - & - & - \\
\hline borneol & 2.90 & - & 0.90 & - & - & - & - & - & - \\
\hline p-cymen-8-ol & - & - & - & 3.80 & - & - & 0.20 & - & - \\
\hline lavandulol & 0.60 & - & 0.40 & - & 0.38 & - & - & - & - \\
\hline terpinen-4-ol & - & - & 0.80 & 0.70 & 0.73 & - & - & - & - \\
\hline sabine ketone & - & - & - & 0.50 & - & - & - & - & - \\
\hline m-cymen-8-ol & - & - & 0.20 & - & - & - & - & - & - \\
\hline$\alpha$-terpineol & 0.50 & - & 0.50 & 1.80 & - & 0.77 & 0.30 & - & - \\
\hline hexyl butyrate & - & - & - & - & - & - & - & - & - \\
\hline isobornyl formate & - & - & - & - & - & - & - & - & - \\
\hline geraniol & - & - & - & - & - & - & - & - & - \\
\hline cumin aldehyde & - & - & - & 1.10 & - & - & - & - & - \\
\hline carvone & - & - & 0.10 & - & - & - & - & - & - \\
\hline linalyl acetate & 27.00 & - & 0.20 & trace & 3.37 & - & - & - & - \\
\hline$\alpha$-bisabolol & - & - & trace & - & - & - & 1.50 & 0.20 & 0.20 \\
\hline dihydrocarveol & - & - & - & - & - & - & - & - & - \\
\hline bornyl acetate & - & 1.32 & trace & - & 0.21 & - & - & - & - \\
\hline lavendulyl acetate & 1.00 & - & 3.21 & - & 1.79 & - & - & - & - \\
\hline verbenone & - & - & 0.60 & 0.40 & - & - & - & - & - \\
\hline neryl acetate & 0.70 & - & - & - & - & - & - & - & - \\
\hline$\beta$-bourbonene & - & - & - & trace & - & - & trace & - & - \\
\hline$\alpha$-trans-bergamotene & - & - & - & trace & - & - & - & - & - \\
\hline$\alpha$-cederene & - & - & - & trace & - & - & - & - & - \\
\hline$\beta$-caryophellene & - & - & - & - & 0.18 & - & 7.60 & 0.80 & 0.90 \\
\hline caryophyllene & 0.70 & - & - & 0.50 & - & trace & - & - & - \\
\hline$\alpha$-santalene & 0.20 & - & - & - & - & - & - & - & - \\
\hline$\alpha$-cis-bergamotene & - & - & - & - & - & - & - & - & - \\
\hline$\beta$-farnesene & 0.30 & - & - & - & - & - & 0.30 & trace & 0.10 \\
\hline germacene D & - & - & 0.10 & - & 1.66 & - & 2.20 & 0.50 & 0.30 \\
\hline$\beta$-bisabolene & - & - & & & & - & 20.80 & 5.60 & 5.00 \\
\hline$\gamma$-cadinene & trace & 0.80 & 0.20 & 0.40 & - & - & - & 0.20 & 0.20 \\
\hline caryophyllene oxide & 0.30 & 0.33 & 0.90 & - & 3.68 & 1.21 & 2.00 & 0.30 & 0.20 \\
\hline spathulenol & - & - & - & 0.30 & - & - & 2.20 & 0.60 & 0.80 \\
\hline cubenol & - & - & trace & - & - & - & - & - & - \\
\hline$\gamma$-muurolol & - & - & - & - & - & - & - & - & - \\
\hline$\tau$-cadinol & - & - & 4.20 & - & - & - & - & 0.20 & 0.30 \\
\hline$\gamma$-terpinene & trace & - & 0.20 & 0.50 & - & - & - & 0.20 & 0.10 \\
\hline octen-3-yl acetate & 0.03 & - & - & - & - & - & - & - & - \\
\hline norborneol acetate & - & - & - & - & - & - & - & - & - \\
\hline
\end{tabular}

France-southern France [11]; Turkey—district of Alahan (Hatay) [17]; Greece (b)—north part of Greece at Chalkidiki peninsula [18]; Algeria-Cherchel (northwest of Algiers region, Algeria) [12]; India (a)—Asangihal village in Sindagi taluk of Bijapur district, India [19]; India (b) —Purandar Fort region [20]; Australia (c)—Randwick, Sydney (Australia) [21]; Portugal (a)—region Sesimbra/Arrábida, south of Portugal [22]; Portugal (b)—region Mértola, south of Portugal [17]. 
Because each lavender oil has a quantitatively and qualitatively distinct profile of chemical compounds, it is necessary to determine the quantity and identity of its individual components (Tables 1 and 2). These data will allow researchers to determine the effects of essential lavender oils on the autochthonous microbiota of the skin. From the literature [23,24], it is known that the chemical composition of oils and their macerates has a decisive influence on their microbiological properties.

Lavender essential oil contains several anti-microbial compounds, such as eucalyptol, linalool, terpinen-4-ol, and $\alpha$-terpineol. Among them, linalool was demonstrated to be the strongest active ingredient against a wide range of microorganisms [8]. Borneol and eucalyptol were identified also as the main compounds in the many essential oils exhibiting anti-parasitic activity [10]. Terpinen-4-ol, $\alpha$-pinene, $\beta$-pinene, 1,8-cineol, linalool, and 4-terpineol also showed high anti-fungal activity against Gram-positive and Gram-negative strains $[25,26]$. Linalool and linalyl acetate have local anaesthetic effects, proven in animal tests (in vivo and in vitro) [25]. Various monoterpenoids, such as $\alpha$-terpineol, terpinen-4-ol, eucalyptol, and linalool, have antiviral activity against influenza strains [26]. Eucalyptol, terpinen-4-ol, thymol, and carvacrol also have extensive anti-inflammatory effects [26].

Composition of the facial skin microbiota varies and depends on many factors, such as proper hygiene, state of health, oiliness, skin hydration, $\mathrm{pH}$, local temperature, and the reduction potential [27]. The skin microbiota contains persistent indigenous microorganisms (so-called residents) that are located on its surface for almost the entire lifespan of the individual, including transitory microorganisms from the environment, animals, food, or water. The microbiota of adult skin [27-29] is mainly formed by Gram-positive cocci (Staphylococcus epidermidis, S. haemolyticus, S. hominis, S. aureus (carrier), Enterococcus faecalis, Micrococcus spp., and Streptococcus), Gram-positive bacilli (Corynebacterium spp., Propionibacterium acnes, P. granulosum, P. avidum, and Bacillus spp.), Gram-negative bacilli (Acinetobacter spp. and Escherichia coli), and yeast-like fungi (Pityrosporum ovale and Candida spp.). Cosmetics containing active anti-bacterial substances of natural origin (essential oils) help to control the growth of microorganisms and additionally have a beneficial effect on the processes taking place on the surface and in the skin. Essential oils accelerate the regeneration and development of skin cells, and, for this reason, the skin becomes stronger and regenerates faster by supporting the processes of granulation of a wounded epidermis [30]. As a result, skin ageing processes are delayed.

The chemical composition and anti-microbial activity of different lavender oils depend on the geographic region of origin, which is why the aim of the present study was to analyse the correlation of the chemical composition of two lavender oils of different origins with their anti-microbial effects on the mixed microbiota of facial skin and on dominant bacterial isolates extracted from the surface of facial skin. The chemical composition and activity of essential lavender oil from the Crimean Peninsula are yet to be published.

\section{Results}

\subsection{Chemical Analysis}

A complex chromatogram was obtained as a result of this analysis, where we identified 101 compounds. Among these identified components, there were 64 oil compounds that were already described in the literature and 37 other compounds, which are yet to be reported (Table 3).

Based on the results, it was found that Crimean lavender oil contains several-fold larger quantities of monoterpenes such as 3-carene, o-cymene, or bicyclic sesquiterpenes (bergamotene isomers, caryophyllene, or $\gamma$-cadinene) as compared with the literature data. In the extract of Crimean lavender, p-cymene-1-ol, 3-octanone, and terpenes were detected at much smaller concentrations, e.g., sabinene or ocimene and sesquiterpene germacrene $\mathrm{D}$. 
Table 3. The components of ETJA and Crimean lavender oils.

\begin{tabular}{|c|c|c|c|c|c|c|}
\hline \multirow{3}{*}{ Name } & \multirow{3}{*}{ Abbreviation } & \multicolumn{2}{|c|}{ RI } & \multicolumn{3}{|c|}{ Oil, Column and Area $(\%) \pm S D$} \\
\hline & & \multirow{2}{*}{ Literat. } & \multirow{2}{*}{ Exper. } & \multirow{2}{*}{$\begin{array}{c}\text { ETJA } \\
\text { ZB-5HT }\end{array}$} & \multicolumn{2}{|c|}{ Crimean } \\
\hline & & & & & HP-5MS & SupelcoWAX \\
\hline tricyclene & B MO & 923 & 920 & - & $0.04 \pm 0.00$ & $0.01 \pm 0.00$ \\
\hline$\alpha$-thujene & B M & 928 & 928 & - & $0.18 \pm 0.01$ & $0.04 \pm 0.00$ \\
\hline$\alpha$-pinene & B M & 936 & 933 & $0.7 \pm 0.01$ & $0.36 \pm 0.01$ & - \\
\hline camphene & B M & 950 & 947 & $0.31 \pm 0.02$ & $0.27 \pm 0.01$ & $0.05 \pm 0.01$ \\
\hline$\beta$-phellandrene & M M & 973 & 973 & $0.09 \pm 0.00$ & $0.09 \pm 0.01$ & - \\
\hline$\beta$-pinene & B M & 978 & 974 & $0.22 \pm 0.01$ & $0.11 \pm 0.01$ & - \\
\hline octen-3-ol & OT & 980 & 983 & $0.04 \pm 0.01$ & $0.61 \pm 0.01$ & $0.16 \pm 0.01$ \\
\hline 3-octanone & OT & 985 & 988 & - & $0.10 \pm 0.01$ & $0.01 \pm 0.01$ \\
\hline$\beta$-myrcene & A M & 989 & 991 & $0.38 \pm 0.02$ & $0.25 \pm 0.01$ & $0.08 \pm 0.00$ \\
\hline 3-carene & B M & 1011 & 1005 & $0.36 \pm 0.01$ & $0.86 \pm 0.01$ & $0.20 \pm 0.01$ \\
\hline sabinene & B M & 1004 & 1009 & - & $0.02 \pm 0.01$ & $0.02 \pm 0.01$ \\
\hline$p$-cymene & $\mathrm{MM}$ & 1024 & 1020 & & $0.22 \pm 0.02$ & - \\
\hline$o$-cymene & $\mathrm{MM}$ & 1041 & 1022 & $0.58 \pm 0.01$ & $1.03 \pm 0.06$ & $0.18 \pm 0.00$ \\
\hline limonene & $\mathrm{M} \mathrm{M}$ & 1029 & 1026 & $19.02 \pm 0.07$ & $0.55 \pm 0.02$ & $0.15 \pm 0.00$ \\
\hline eucalyptol & $\mathrm{B} \mathrm{MO}$ & 1031 & 1027 & - & $5.00 \pm 0.10$ & $1.66 \pm 0.02$ \\
\hline$(E)$ - $\beta$-ocimene & $\mathrm{A} \mathrm{M}$ & 1048 & 1040 & & $0.99 \pm 0.01$ & $0.44 \pm 0.01$ \\
\hline (Z)- $\beta$-ocimene & A M & 1037 & 1049 & $0.02 \pm 0.01$ & $0.75 \pm 0.02$ & $0.41 \pm 0.01$ \\
\hline trans-linalool oxide & A MO & 1083 & 1070 & $0.05 \pm 0.01$ & $0.53 \pm 0.03$ & $0.08 \pm 0.00$ \\
\hline$\beta$-citral & $\mathrm{AM}$ & 1245 & 1084 & - & $0.08 \pm 0.01$ & - \\
\hline cis-linalool oxide & A MO & 1075 & 1091 & $0.15 \pm 0.01$ & $0.52 \pm 0.02$ & $0.07 \pm 0.01$ \\
\hline trans-sabinene hydrate & $\mathrm{B} \mathrm{MO}$ & 1098 & 1097 & - & $0.10 \pm 0.04$ & $0.04 \pm 0.00$ \\
\hline linalool & A MO & 1099 & 1105 & $41.84 \pm 0.10$ & $34.13 \pm 0.25$ & $52.71 \pm 0.33$ \\
\hline cis- $p$-menth-2-en-1-ol & $\mathrm{MMO}$ & 1123 & 1116 & - & $0.01 \pm 0.00$ & - \\
\hline trans-pinocarveol & $\mathrm{B} \mathrm{MO}$ & 1140 & 1135 & - & $0.04 \pm 0.01$ & - \\
\hline camphor & $\mathrm{B} \mathrm{MO}$ & 1143 & 1141 & $0.15 \pm 0.01$ & $0.54 \pm 0.01$ & $0.09 \pm 0.01$ \\
\hline myrtenol & $\mathrm{B} \mathrm{MO}$ & 1150 & 1146 & $0.19 \pm 0.01$ & $0.08 \pm 0.04$ & - \\
\hline borneol & $\mathrm{B} \mathrm{MO}$ & 1166 & 1168 & - & $1.50 \pm 0.01$ & - \\
\hline p-cymen-8-ol & $\mathrm{B} \mathrm{MO}$ & 1184 & 1171 & - & $0.04 \pm 0.01$ & $0.03 \pm 0.00$ \\
\hline lavandulol & A MO & 1168 & 1175 & $0.18 \pm 0.01$ & $0.54 \pm 0.01$ & $0.11 \pm 0.02$ \\
\hline terpinen-4-ol & $\mathrm{MMO}$ & 1177 & 1181 & $0.29 \pm 0.01$ & $6,66 \pm 0.04$ & $2.29 \pm 0.02$ \\
\hline sabine ketone & $\mathrm{B} \mathrm{MO}$ & 1194 & 1190 & - & $0.50 \pm 0.02$ & $0.08 \pm 0.00$ \\
\hline$m$-cymen-8-ol & $\mathrm{B} \mathrm{MO}$ & 1180 & 1192 & $0.03 \pm 0.01$ & $0.16 \pm 0.01$ & $0.03 \pm 0.00$ \\
\hline$\alpha$-terpineol & $\mathrm{M} \mathrm{MO}$ & 1190 & 1197 & $0.07 \pm 0.00$ & $1.54 \pm 0.03$ & - \\
\hline hexyl butyrate & OT & 1191 & 1203 & - & $0.63 \pm 0.02$ & - \\
\hline isobornyl formate & $\mathrm{B} \mathrm{MO}$ & 1240 & 1230 & - & $0.13 \pm 0.01$ & $0.61 \pm 0.01$ \\
\hline geraniol & A MO & 1255 & 1234 & $0.02 \pm 0.01$ & $0.08 \pm 0.01$ & $0.03 \pm 0.01$ \\
\hline cumin aldehyde & $\mathrm{MMO}$ & 1238 & 1242 & - & $0.18 \pm 0.00$ & $0.03 \pm 0.00$ \\
\hline carvone & $\mathrm{M} \mathrm{MO}$ & 1242 & 1245 & $0.04 \pm 0.01$ & $0.05 \pm 0.01$ & $0.01 \pm 0.00$ \\
\hline linalyl acetate & $\mathrm{A} \mathrm{MO}$ & 1255 & 1259 & $32.70 \pm 0.08$ & $23.29 \pm 0.30$ & $36.56 \pm 0.34$ \\
\hline$\alpha$-bisabolol & M SO & 1282 & 1266 & - & $0.03 \pm 0.01$ & - \\
\hline dihydrocarveol & $\mathrm{MMO}$ & 1194 & 1277 & - & $0.05 \pm 0.07$ & - \\
\hline bornyl acetate & $\mathrm{B} \mathrm{MO}$ & 1283 & 1278 & - & $0.15 \pm 0.01$ & $0.04 \pm 0.01$ \\
\hline lavendulyl acetate & A MO & 1289 & 1285 & $0.06 \pm 0.01$ & $2.45 \pm 0.02$ & $0.51 \pm 0.01$ \\
\hline verbenone & $\mathrm{B} \mathrm{MO}$ & 1206 & 1296 & - & $0.04 \pm 0.01$ & - \\
\hline neryl acetate & A MO & 1363 & 1359 & $0.39 \pm 0.02$ & $0.22 \pm 0.01$ & $0.05 \pm 0.01$ \\
\hline$\beta$-bourbonene & B S & 1384 & 1373 & - & $0.05 \pm 0.00$ & $0.01 \pm 0.00$ \\
\hline$\alpha$-trans-bergamotene & B S & 1434 & 1382 & - & $0.17 \pm 0.01$ & - \\
\hline$\alpha$-cedrene & B S & 1412 & 1398 & - & $0.06 \pm 0.00$ & - \\
\hline$\beta$-caryophellene & B S & 1406 & 1402 & - & $0.11 \pm 0.10$ & - \\
\hline caryophyllene & B S & 1420 & 1408 & $0.5 \pm 0.01$ & $4.19 \pm 0.10$ & $1.63 \pm 0.02$ \\
\hline$\alpha$-santalene & B S & 1421 & 1411 & - & $1.05 \pm 0.03$ & $0.23 \pm 0.01$ \\
\hline$\alpha$-cis-bergamotene & B S & 1414 & 1429 & - & $0.28 \pm 0.00$ & $0.02 \pm 0.00$ \\
\hline$\beta$-farnesene & A S & 1456 & 1454 & $0.1 \pm 0.01$ & $0.96 \pm 0.01$ & $0.28 \pm 0.02$ \\
\hline germacene D & A S & 1481 & 1496 & - & $0.03 \pm 0.02$ & - \\
\hline$\beta$-bisabolene & MS & 1508 & 1504 & - & $0,02 \pm 0.01$ & - \\
\hline$\gamma$-cadinene & B S & 1513 & 1507 & - & $0.53 \pm 0.01$ & - \\
\hline caryophyllene oxide & B SO & 1581 & 1572 & - & $2.59 \pm 0.01$ & $0.29 \pm 0.00$ \\
\hline spathulenol & B SO & 1576 & 1601 & - & $0.02 \pm 0.00$ & - \\
\hline
\end{tabular}


Table 3. Cont.

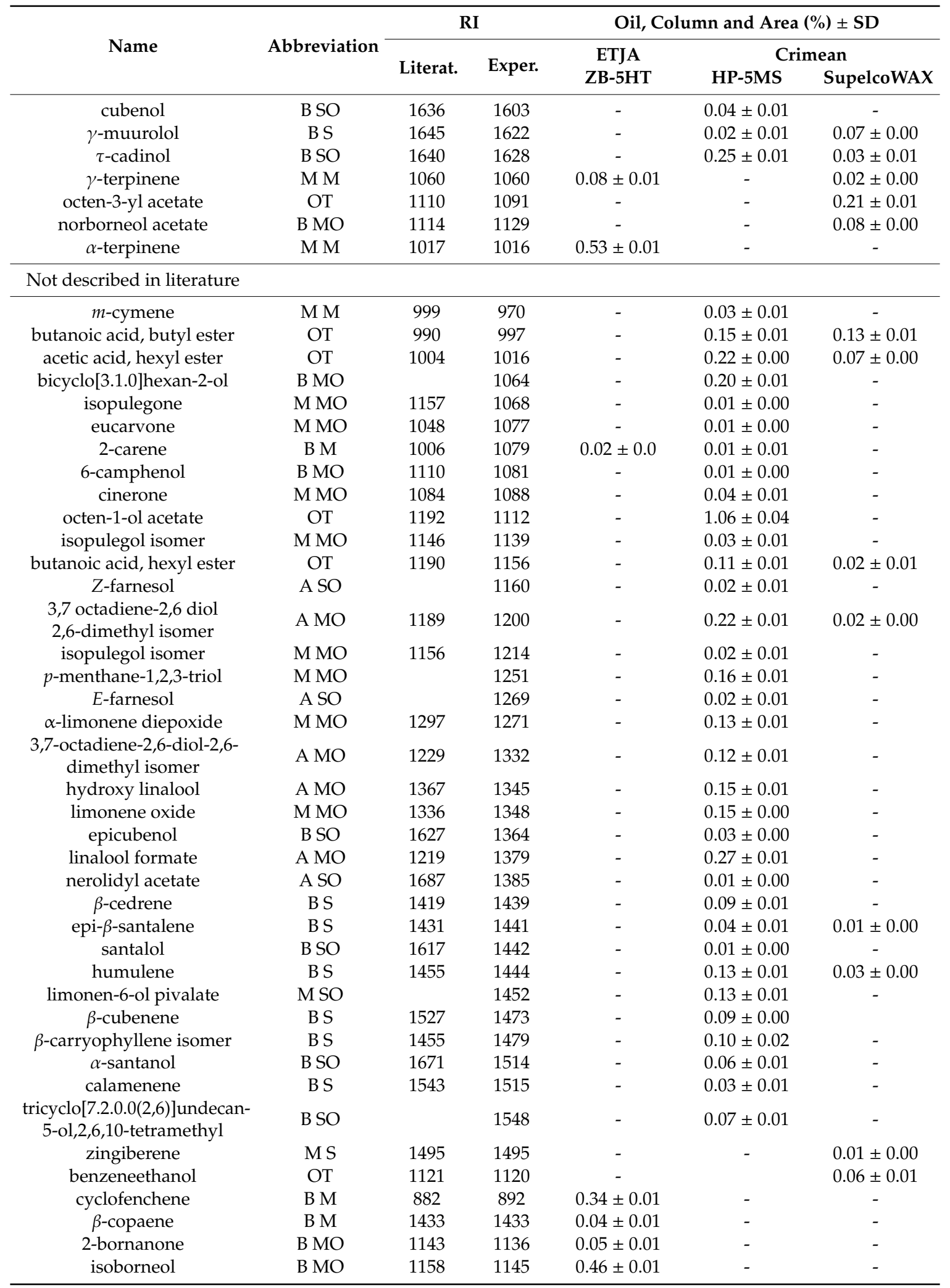

Abbreviations: A M-aliphatic monoterpenes; M M-monocyclic monoterpenes; B M-bi- and tricyclic monoterpenes; $\mathrm{A} \mathrm{MO}$ —aliphatic monoterpenoids; $\mathrm{M} \mathrm{MO}$ —-monocyclic monoterpenoids; $\mathrm{B} \mathrm{MO}$ - bi- and tricyclic monoterpenoids; A S-aliphatic sesquiterpenes; M S - monocyclic sesquiterpenes; B S — bi- and tricyclic sesquiterpenes; A SO-aliphatic sesquiterpenoids; M SO-monocyclic sesquiterpenoids; B SO-bi- and tricyclic sesquiterpenoids. SD—standard deviation; RI-retention indexes; literat.-literature data; exper-—determined experimentally for the non-polar columns: HP-5MS for CRIMEA oil and ZB-5HT for ETJA oil. 
Analysis of hexane solutions of lavender essential oil was performed too (on the SupelcoWAX column), and the average retention parameters and peak areas are listed in Table 3. Less complex chromatograms and worse separation of the sample components were obtained in this assay; specifically, the peaks corresponding to the main components of oil were close to one another and were not completely separated.

GC-MS analysis on the SupelcoWAX column allowed us to identify 50 compounds contained in Crimean lavender essential oil. Among these compounds, 42 were already described in the literature. Three components of lavender oil-which were already described in the literature-could not be identified by means of the HP-5MS column but could be identified using the SupelcoWAX column. These compounds included $\gamma$-terpinene, octene-3-yl acetate, and norborneol acetate.

Furthermore, eight previously undescribed components were identified, including the five already identified via the HP-5MS column. In addition, the presence of three small peaks corresponding to benzoic acid, butyric acid, zingiberene, and 2-phenylethanol was detected.

Moreover, sharp, clear-cut, and completely separated peaks of limonene (1) and eucalyptol (2) for 1:10 dilutions were obtained using this column. They could not be analysed by means of the HP-5MS column. In the case of samples with the dilution of 1:10, overlapping limonene (1) and eucalyptol (2) peaks were observed. Some improvement of separation of these components of lavender oil was achieved by greater dilution, but only the use of polar columns yielded satisfactory results. The comparison of separation of these two terpenes at different dilutions on both columns is shown in Figure 1.
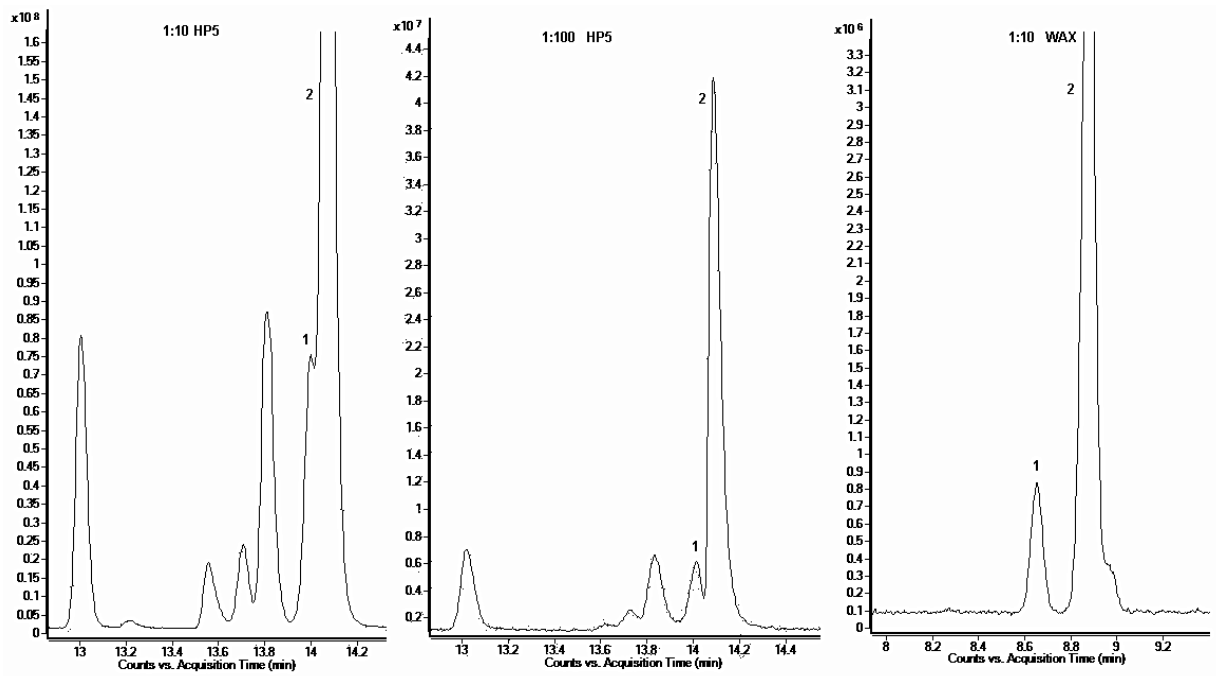

Figure 1. Comparison of limonene (1) and eucalyptol (2) peak separation, between the HP-5MS column at a dilution of $1: 10(v / v)$ or 1:100 $(v / v)$ and the SupelcoWAX ${ }^{\mathrm{TM}} 10$ column at dilution 1:10 $(v / v)$.

From the presented data, it can be concluded that the separation of Crimean lavender oil on the polar column was not satisfactory; better results were obtained on the non-polar column. Therefore, only this column was employed to determine the chemical composition of ETJA lavender oil.

On the basis of the conducted studies, it was demonstrated that the tested lavender oils differ in chemical composition and anti-microbial activity both quantitatively and qualitatively. In ETJA oil (Table 3), 33 components were identified, including 28 already described in the literature, as well as five compounds not described previously (2-carene, cyclofenchene, $\beta$-copaene, 2-bornanone, and isoborneol).

ETJA lavender oil turned out to contain higher concentrations of linalool (41.8\%), linalyl acetate $(32.7 \%)$, and limonene (19.0\%), whereas Crimean lavender oil contained linalool (34.1\% according to HP-5MS column analysis or $52.7 \%$ in accordance with the SupelcoWAX column analysis), linalyl acetate (23.3\% according to the HP-5MS column analysis or $36.6 \%$ according to the SupelcoWAX column 
analysis), and eucalyptol (5.0\% in accordance with the HP-5MS column analysis or $1.7 \%$ judging by the SupelcoWAX column analysis; Table 3). ETJA lavender oil was composed mainly of monoterpenoids (76.7\%) and monoterpenes (22.7\%), whereas Crimean lavender oil was found to be composed mainly of monoterpenoids $(80.1 \%$ according to the HP-5MS column analysis or $95.1 \%$ in accordance with the SupelcoWAX column analysis), much less monoterpenes (5.8\% according to the HP-5MS column analysis or $1.6 \%$ judging by the SupelcoWAX column analysis), and some sesquiterpenes $(8.0 \%$ in accordance with the HP-5MS column analysis or $2.3 \%$ judging by the SupelcoWAX column analysis; Table 4).

Table 4. The list of terpenes in the tested lavender oils.

\begin{tabular}{ccccc}
\hline & & \multicolumn{2}{c}{ Oil, Column and Area (\%) } \\
\cline { 3 - 5 } & Abbreviation & ETJA & \multicolumn{2}{c}{ Crimean } \\
& & ZB-5HT & HP-5MS & SupelcoWAX \\
\hline Aliphatic monoterpenes & A M & 0.40 & 2.07 & 0.93 \\
Monocyclic monoterpenes & M M & 20.30 & 1.92 & 0.35 \\
Bi- and tricyclic monoterpenes & B M & 1.99 & 1.81 & 0.31 \\
\hline Monoterpenes & M & $\mathbf{2 2 . 6 9}$ & $\mathbf{5 . 8 0}$ & $\mathbf{1 . 5 9}$ \\
\hline Aliphatic monoterpenoids & A MO & 75.39 & 62.52 & 90.14 \\
Monocyclic monoterpenoids & M MO & 0.40 & 9.04 & 2.33 \\
Bi- and tricyclic monoterpenoids & B MO & 0.88 & 8.53 & 2.67 \\
\hline Monoterpenoids & MO & $\mathbf{7 6 . 6 7}$ & $\mathbf{8 0 . 0 9}$ & $\mathbf{9 5 . 1 4}$ \\
\hline Aliphatic sesquiterpenes & A S & 0.10 & 0.99 & 0.28 \\
Monocyclic sesquiterpenes & M S & - & 0.02 & 0.01 \\
Bi- and tricyclic sesquiterpenes & B S & 0.50 & 6.94 & 2.00 \\
\hline Sesquiterpenes & S & $\mathbf{0 . 6 0}$ & $\mathbf{7 . 9 5}$ & $\mathbf{2 . 2 9}$ \\
\hline Aliphatic sesquiterpenoids & A SO & - & 0.05 & - \\
Monocyclic sesquiterpenoids & M SO & - & 0.16 & - \\
Bi- and tricyclic sesquiterpenoids & B SO & - & 3.07 & 0.32 \\
\hline Sesquiterpenoids & SO & - & 3.28 & $\mathbf{0 . 3 2}$ \\
\hline Others & OT & $\mathbf{0 . 0 4}$ & $\mathbf{2 . 8 8}$ & $\mathbf{0 . 6 6}$ \\
\hline
\end{tabular}

\subsection{Biological Analysis}

The effect of lavender oils on the mixed microbiota of the face skin without signs of lesions depended on the origin of the oil and the concentration used. ETJA lavender oil at all concentrations tested reduced the number of skin microbial cells 1000-10,000-fold, compared to the control. The strongest microbial cell number reduction was observed after application of $70 \mu \mathrm{L} / \mathrm{cm}^{3}$ oil and slightly less at $50 \mu \mathrm{L} / \mathrm{cm}^{3}$ (Figure 2). On the other hand, Crimean lavender oil exerted much weaker anti-microbial activity, and only at the highest concentration did it suppress the growth of the microbiota hundred-fold (Figure 2).

Lavender oils, depending on their origin, also had a different influence on the qualitative changes in the facial skin microbiota. In the presence of the highest concentration of ETJA lavender oil tested, bacteria of the following species survived: Micrococcus luteus, E. coli, Staphylococcus warneri, and Enterococcus faecium. Crimean lavender oil, however, did not inhibit the growth of Bacillus (B. cereus, B. subtilis, and B. mycoides), Corynebacterium spp., E. faecium, and S. warneri. The most sensitive to ETJA lavender oil were Gram-positive bacilli, and Gram-negative bacilli were the most sensitive to Crimean lavender oil. On the other hand, none of the tested oils inhibited the growth of Gram-positive cocci.

Therefore, an attempt was made to determine those oil concentrations which would effectively decrease the growth of individual isolates. Inhibitory effects on the growth of bacterial isolates that survived in a mixed microbial population from facial skin were exerted by the tested oils only at 
concentrations between 40 and $80 \mu \mathrm{L} / \mathrm{cm}^{3}$ and growth inhibition zones between 12.5 and $44 \mathrm{~mm}$, with higher effectiveness of oils at the highest concentrations. ETJA lavender oil was more effective because it limited the growth of most bacteria under study, including Bacillus. Neither of the oils tested inhibited the growth of E. faecium (Table 5, Figure 3).

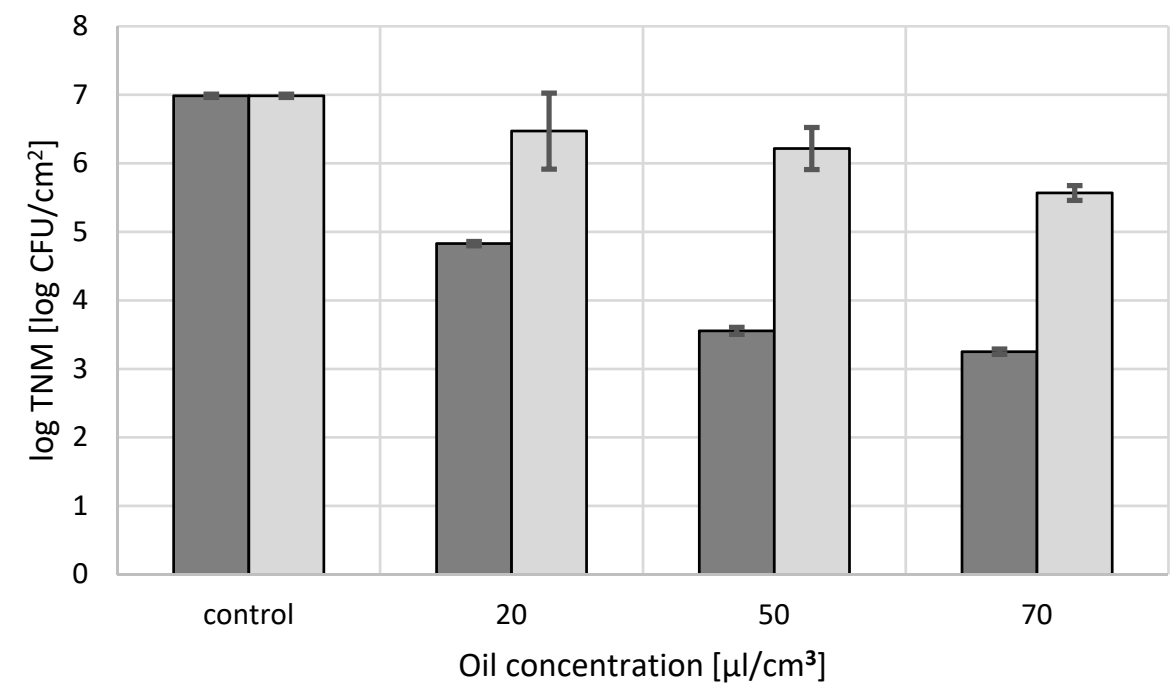

口ETJA ICRIMEA

Figure 2. The influence of concentrations of the lavender oils under study on the number of microbiota cells from facial skin.

A.

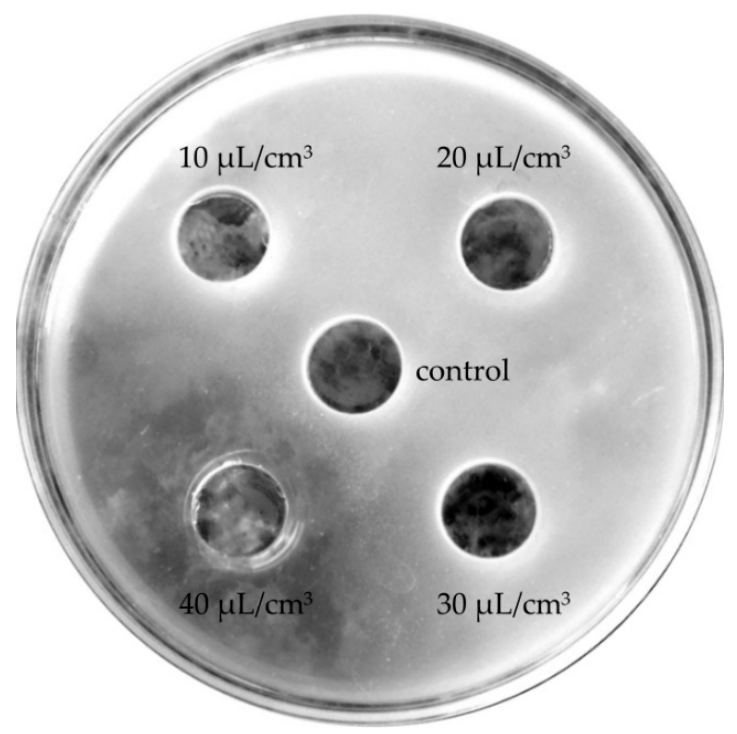

B.

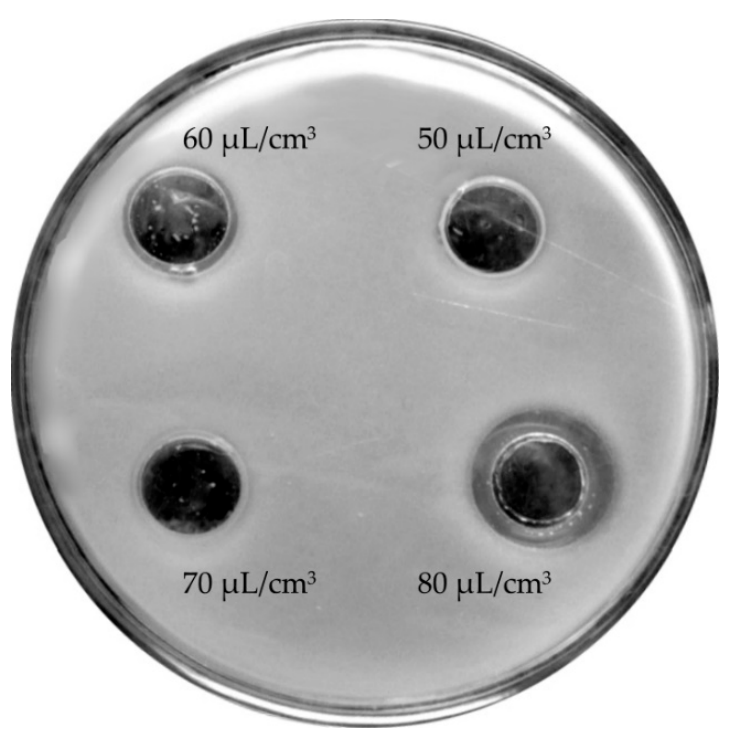

Figure 3. Zones of growth inhibition of a Bacillus cereus isolate in the presence of tested concentrations $\left(10-80 \mu \mathrm{L} / \mathrm{cm}^{3}\right)$ of lavender oils: (A) ETJA, $40 \mu \mathrm{L} / \mathrm{cm}^{3}$; (B) Crimean lavender oil, $80 \mu \mathrm{L} / \mathrm{cm}^{3}$.

At lower concentrations (10-40 $\mu \mathrm{L} / \mathrm{cm}^{3}$ ), lavender oils manifested neutral effects (Figure 4 ) or, as in the case of Crimean lavender oil, stimulated bacterial growth (Figure 5). 


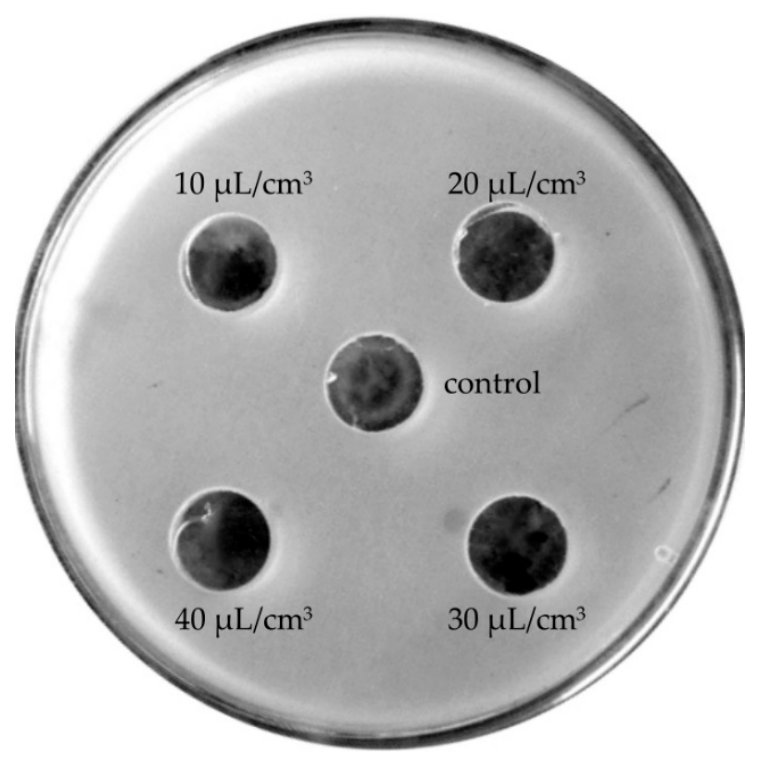

Figure 4. Neutral effects of lavender oils on the growth of the bacterial species Enterococcus faecium.

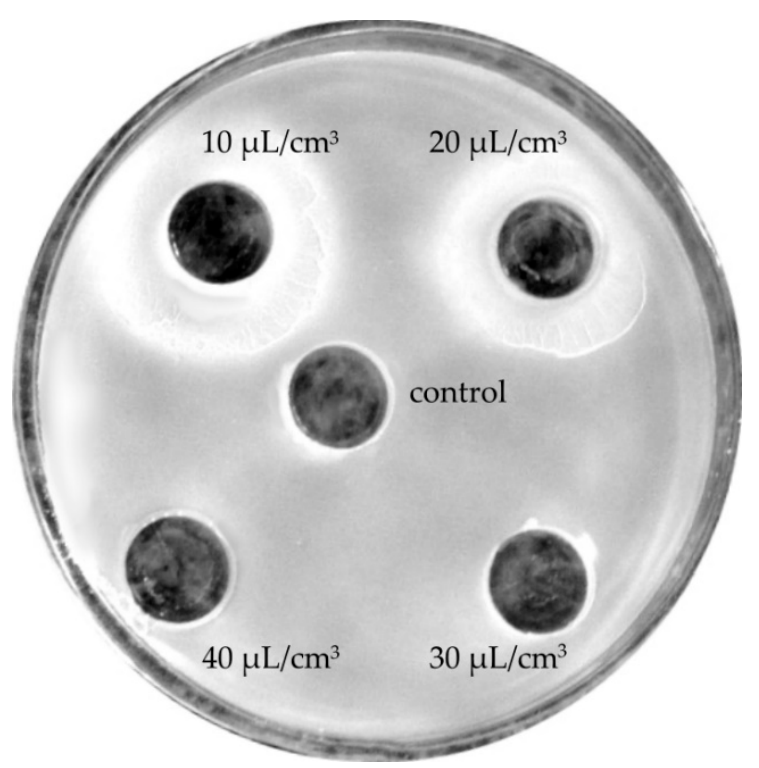

Figure 5. Stimulation of Bacillus mycoides growth in the presence of a low concentration $\left(10\right.$ or $\left.20 \mu \mathrm{L} / \mathrm{cm}^{3}\right)$ of Crimean lavender oil.

Table 5. Zones of growth inhibition of dominant bacterial isolates.

\begin{tabular}{cccc}
\hline \multirow{2}{*}{ Species of Isolates } & $\begin{array}{c}\text { Oil Concentration } \\
\left(\boldsymbol{\mu} \mathbf{L} / \mathbf{c m}^{\mathbf{3}}\right)\end{array}$ & \multicolumn{2}{c}{ Zones of Inhibition $(\mathbf{m m}) \pm \mathbf{S D}$} \\
\cline { 3 - 4 } & 40 & $47.0 \pm 4.2$ & Crimean \\
\hline Bacillus cereus & 80 & $40.0 \pm 3.5$ & $19.5 \pm 0.7$ \\
Bacillus subtilis & 80 & $23.5 \pm 0.7$ & 0 \\
Bacillus mycoides & 60 & $33.0 \pm 1.4$ & 0 \\
Staphylococcus warneri & 80 & $22.8 \pm 0.4$ & 0 \\
Micrococcus luteus & 80 & $19.0 \pm 1.4$ & $12.5 \pm 0.7$ \\
Enterococcus faecium & 80 & 0 & 0 \\
Corynebacterium spp. & 50 & $18.5 \pm 0.7$ & $13.0 \pm 1.4$ \\
Escherichia coli & 80 & 0 & $16.0 \pm 1.4$ \\
\hline
\end{tabular}


To sum up, the tested lavender oils reduced the mixed population of microbes from facial skin, but ETJA lavender oil with higher amounts of monoterpenoids (linalool and linalyl acetate) and monoterpenes (limonene) was characterised by higher effectiveness than Crimean lavender oil.

\section{Discussion}

Shortly after birth, the human skin is immediately colonised by microorganisms, such as bacteria, yeasts, fungi, and viruses. Nonetheless, the composition of the skin microbiota varies quantitatively and qualitatively, and it depends on humidity, temperature, $\mathrm{pH}$, and body area [27]. A child's skin is mainly colonised by bacteria of genus Staphylococcus, Enterococcus, Corynebacterium, and Escherichia, and, in the teenage period, by Sarcina. At an elderly age, however, an increase in the number of fungal cells is observed, mainly Candida albicans yeast [27-29].

The challenge in skincare is oily skin because it has to be properly cleaned and moisturised, but comedogenic agents (which block sebaceous glands, resulting in blackheads) cannot be used [27,31,32]; therefore, biological substances effective at low concentrations are sought for care for this type of skin. Lavender oil is a strong antiseptic. Therefore, it is an additive to pharmaceuticals (salve and lotions for hard-to-heal wounds, eczema, and anti-rheumatic preparations), as well as cosmetics. It is used in mouth, throat, upper respiratory tract, and lung infectious diseases, as well as in dermatology to treat difficult-to-heal wounds, ulcers, and burns, and in cosmetology. However, the anti-microbial effect of lavender oil depends on the species and the variety of lavender from which it is obtained. Cavanagh and Wilkinson [33] and Sienkiewicz et al. [34] showed that the anti-microbial activity of essential oils depends on their chemical composition. According to literature data, Lavandula angustifolia oil has the most variable chemical composition. Bulgarian lavender oil contains ocimene (6.8-7.7\%), linalool (30-34\%), and linalyl acetate (35-38\%), while it does not contain lavandulol and lavandulol acetate. The main ingredients in oils from China and India were linalool, linalool acetate, and lavandulol, all found in various amounts; however, ocimene was not identified [14,35]. Adaszyńska et al. [36] showed that the highest content of linalool was found in essential oils from the variety "Lavender Lady" and "Elegance Purple" (23.9\% and 22.4\%). At the same time, these oils contained small amounts of cis- $\beta$-ocimene. The best anti-bacterial properties against $S$. aureus and Pseudomonas aeruginosa were found in oils obtained from varieties "Blue River" and "Munstead". Essential oil obtained from Lavandula angustifolia Mill. has strong bactericidal properties against methicillin-resistant Staphylococcus aureus (MRSA) and vancomycin-resistant Enterococcus sp. (VRE) [33]. Essential oil from Lavandula heterophylla "Avonview" inhibits growth of Streptococcus pyogenes, Enterobacter aerogenes, Staphylococcus aureus MRSA, Pseudomonas aeruginosa, Citrobacter freundii, Proteus vulgaris, Escherichia coli VRE, Shigella sonnei, and Propionibacterium acnes $[33,37]$. A suitable substance may be lavender oil, which, according to the manufacturer, can be added even at a concentration of $\sim 5 \%$ to cosmetic preparations and pharmaceuticals. At this concentration, lavender oil has a strong effect on some types of skin without irritation; however, more sensitive skin requires preparations with lower lavender oil content, and, during a disease with relevant symptoms, preparations with a higher concentration of lavender oil.

The scientific literature mainly contains the results of studies on the effects of lavender oils (obtained from many varieties of lavender by various research techniques) on selected individual isolates of microorganisms. Sabara and Kunicka-Styczyńska [38] reported that lavender oil (from Lavandula angustifolia) at concentrations of $100-200 \mu \mathrm{L} / \mathrm{cm}^{3}$ inhibited the growth of all tested microorganisms-E. coli, Bacillus subtilis, Candida mycoderma, and Aspergillus niger-and the inhibitory effect on Bacillus bacteria and Aspergillus fungi growth was obtained at a 10 -fold lower dose $(10 \mu \mathrm{L} / \mathrm{mL})$. Roller et al. [39], when comparing the anti-microbial efficacy of several lavender oils (from different varieties of the plant), tested them individually, as well as in mixtures, against methicillin-resistant and non-methicillin-resistant $S$. aureus and noted that the best anti-microbial effects were obtained by combining several oils. In other studies, lavender oil at concentrations below 2000 ppm (parts per million) was less active against bacteria of the genera Bacillus, Lactobacillus, Clostridium, and Bifidobacterium [40]. 
The obtained results showed a significant reduction in the number of microbial cells in the mixed population from the skin at the dose of $50 \mu \mathrm{L} / \mathrm{cm}^{3}$ lavender oil, but the most effective was lavender oil at the concentration of $70 \mu \mathrm{L} / \mathrm{cm}^{3}$, although no complete inhibition of the growth of the mixed microbiota from the skin was observed.

After application of ETJA lavender oil to the mixed microbiota from the skin, bacteria M. luteus, E. coli, S. warneri, and E. faecium survived, whereas, after the application of Crimean lavender oil, Bacillus (B. cereus, B. subtilis, and B. mycoides), Corynebacterium sp., E. faecium, and S. warneri survived. Only oils at concentrations between 40 and $80 \mu \mathrm{L} / \mathrm{cm}^{3}$ inhibited the growth of individual bacterial isolates, whereby oils used at the highest concentrations showed higher effectiveness. ETJA lavender oil inhibited the growth of most bacteria tested, including Bacillus, but neither oil inhibited the growth of E. faecium.

The most sensitive to ETJA lavender oil were Gram-positive bacilli, and Gram-negative bacilli were the most sensitive to Crimean lavender oil. On the other hand, neither of the tested oils inhibited the growth of Gram-positive cocci.

The essence of the effect of lavender oils on skin microbiota depends on the quantitative and qualitative chemical composition. Essential oils have an affinity for lipid cell structures; therefore, they destroy the cell wall and membranes of bacteria, mainly Gram-positive ones (less often Gram-negative) and fungi, and, as a consequence, there is leakage and coagulation of the cytoplasm. In addition, lavender oils inhibit the synthesis of RNA, DNA, proteins, and polysaccharides, while, in fungi, they act as anti-mycotics and inhibit the production of enzymes [40].

Monoterpenes, especially linalool, have an anti-microbial effect on bacteria. The mechanism of action consists of disturbing the lipid structure of cell membranes and increasing the permeability of these membranes to monoterpenes, which—by penetrating bacterial cells—block their metabolism, thereby leading to cell death [41].

According to the literature, the spectrum of action of lavender oil is broad because it has anti-viral and anti-fungal properties, in addition to bactericidal activity. Studies conducted by Minami et al. [42] revealed that narrow-leaved lavender (L. latifolia) spike oil at a concentration of $1 \%$ suppressed the replication of a herpes virus in vitro. According to those researchers, this outcome can be explained by the impact of oil components on the areola and virus glycoprotein [42].

Our study indicates that the main components of the tested Crimean lavender oil are similar to those of oils extracted from two species of lavender: L. angustifolia from Australia [13] and Lavandin abrialis from France [11]. Much greater differences from the literature data were observed here in the components present in the tested oils in quantities not exceeding $1 \%$. Crimean lavender oil is characterised by several-fold higher concentration of terpenes such as 3-carene, $o$-cymene, caryophyllene, and bergamotene as compared to other lavender oils. Nonetheless, sabinene, ocimene, and germacrene $\mathrm{D}$ were present in much smaller quantities. In addition, we were able to identify other terpene compounds not yet reported as components of lavender oil. These include terpene alcohols (geraniol, farnesol, santalol, isopulegol, and cubenol), terpene aldehydes (citral), and terpene ketones (verbenone, cinerone, and eucarvone).

\section{Materials and Methods}

\subsection{Materials}

The research experiments consisted of two oils: commercial lavender essential oil (Lavandula angustifolia Oil) from ETJA (produced by ETJA, Elblag, Poland) and Crimean lavender oil (Lavandula angustifolia Oil) from lavender grown in the gardens of the Institute of Essential Oil of the Ukrainian Academy of Agricultural Sciences in Simferopol, Crimea, Ukraine. Both oils were obtained by steam distillation. 


\subsection{Gas Chromatography with Mass Spectrometry (GC-MS)}

The analysis of Crimean lavender oil was performed at the Institute of Heavy Organic Synthesis "Blachownia" in Kędzierzyn-Koźle on an Agilent Technologies Gas Chromatograph 7890 GC (Agilent, Santa Clara, CA, USA) system coupled with a mass spectrometer, GC-MS 7000-Triple Quad (Agilent, Santa Clara, CA, USA). Two types of capillary columns of different polarity-non-polar HP-5MS (5\% diphenyl, 95\% dimethylpolysiloxane, Agilent J\&W, Palo Alto, CA, USA) and SupelcoWAX ${ }^{\mathrm{TM}}$ 10 polar (polyethylene glycol Carbowax®20M, Merck KGaA, Darmstadt, Germany)—were employed; both columns had a length of $30 \mathrm{~m}$, internal diameter of $0.25 \mathrm{~mm}$, and film thickness of 0.25 microns. Helium served as the carrier gas, and its flow rate was $1.5 \mathrm{~mL} / \mathrm{min}$. Analyses were performed in the temperature range $45-250^{\circ} \mathrm{C}$; the initial temperature was maintained for $6 \mathrm{~min}$, and the heating rate was $3^{\circ} \mathrm{C} / \mathrm{min}$. Samples with a volume of $0.5 \mathrm{~mL}$ were prepared by means of an auto-sampler. The gas chromatograph was equipped with a split injector; the split ratio was 100:1. Injector temperature was $250{ }^{\circ} \mathrm{C}$. The test solutions were prepared by diluting an oil sample with $n$-hexane at a volume ratio of 1:10 or $1: 100$.

ETJA lavender oil was analysed in the Faculty of Chemistry, University of Opole, on a Hewlett Packard HP 6890 series GC system chromatograph (Hewlett Packard, Waldbronn, Germany), which was coupled with a Hewlett Packard 5973 mass selective detector (Hewlett Packard, Waldbronn, Germany). The chromatograph was equipped with the non-polar, high-temperature ZB-5HT capillary column (length, $30 \mathrm{~m}$; inner diameter, $0.32 \mathrm{~mm}$; film thickness, $0.25 \mu \mathrm{m}$, Phenomenex Inc., Torrance, CA, USA). Helium served as the carrier gas, and its flow rate was $2 \mathrm{~mL} / \mathrm{min}$. Assays were performed in the temperature range $60-280^{\circ} \mathrm{C}$, and the heating rate was $10^{\circ} \mathrm{C} / \mathrm{min}$; the auxiliary temperature was $300^{\circ} \mathrm{C}$. Samples with a volume of $1 \mathrm{~mL}$ were manually dosed. The gas chromatograph was equipped with an on-column injector with programmable temperature (the same as the analysis temperature). The test solutions were prepared by diluting an oil sample with dichloromethane at a volume ratio of 1:10 or 1:100.

Components were identified by comparison of their mass spectra with the spectrometer database of the NIST 11 Library (National Institute of Standards and Technology, Gaithersburg, MD, USA) and by comparison of their retention index calculated against $n$-alkanes $\left(C_{9}-C_{20}\right)$. Each chromatographic analysis was repeated three times. The average values of relative composition of essential oil (percentages) were calculated from the peak areas.

\subsection{Biological Experiment}

The object of this experiment was the microbiota of oily facial skin without signs of lesions; the microbiota was isolated by a surface swab, and two lavender oils of various origins-from the ETJA company (ETJA, Elblag, Poland) and oil extracted from Crimean lavender (not yet described in the literature)-were employed at concentrations $10-80 \mu \mathrm{L} / \mathrm{cm}^{3}$.

The biological material was collected from five areas of facial skin, i.e., the cheeks, nose, forehead, and chin (i.e., from a total area of $20 \mathrm{~cm}^{2}$ ) and was resuspended in broth (control) and in broth with the addition of tested lavender oils at concentrations of 20,50, and $70 \mu \mathrm{L} / \mathrm{cm}^{3}$ (a concentration of $50 \mu \mathrm{L} / \mathrm{cm}^{3}$ is recommended by the manufacturers when this oil serves as an additive in cosmetic and pharmaceutical preparations). Because the effectiveness of an oil in suppressing the growth of the skin microbiota depends on the concentration and origin of the oil, lower and higher concentrations than those recommended by the manufacturer were tested. The samples were incubated for $24 \mathrm{~h}$ at a temperature of $35^{\circ} \mathrm{C}$.

The anti-microbial effects of these oils on the mixed microbiota from facial skin were evaluated by the surface culture method (10-fold dilutions in water containing $0.05 \%$ Tween-80) in parallel with the Nutrient LAB Agar ${ }^{\mathrm{TM}}$ medium by the BIOCORP company (BIOCORP, Warszawa, Poland) for determination of the bacterial cell count and in addition to selective media (Braid-Parker, Enterococcus agar, Hektoena, ENDO, and Pseudomonas agar) of the BTL company (BTL sp. z o.o., Łódź, Poland) for determination of a cell count of potentially pathogenic bacteria. After incubation, the total 
number of lavender oil-non-sensitive bacteria was determined, and the results were expressed in $\log$ colony-forming units (CFU)/ $\mathrm{cm}^{2}$ of the facial skin surface. The dominant bacterial isolates were identified by API tests from BIOMERIEUX company (BIOMERIEUX SSC Europe Sp. z o.o., Warszawa, Poland; ID32GN: Gram-negative bacilli, 50CHB: Gram-positive bacilli, ID32 STAPH: Gram-positive cocci). In the presence of the highest concentration of ETJA lavender oil used, bacteria of the following species survived: Micrococcus luteus, Escherichia coli, Staphylococcus warneri, and Enterococcus faecium. In the presence of the highest concentration of Crimea oil used, bacteria of the following species survived: Bacillus cereus, B. subtilis, B. mycoides, Corynebacterium spp., and Enterococcus faecium.

Next, the bactericidal activities of the tested oils on these dominant bacterial isolates were evaluated by the diffusion cylinder plate method on Nutrient LAB Agar ${ }^{\mathrm{TM}}$ medium [43]. The media were inoculated with $1 \mathrm{~cm}^{3}$ of a standard bacterial suspension with the optical density of $\zeta=2$ at a wavelength of $550 \mathrm{~nm}$. The results were presented as a mean value of the growth inhibition diameter (in $\mathrm{mm}$ ). The inhibitory effect was assumed to be the lack of growth around wells, whereas growth stimulation intensified growth around wells, and the neutral effect caused growth inhibition at the edges of the wells. The control was water containing $0.05 \%$ Tween- 80 . The essential oils and extracts were used at the following concentrations: $10,20,30,40,60,70$, or $80 \mu \mathrm{L} / \mathrm{cm}^{3}(v / v)$. Each experiment was repeated three times.

\section{Conclusions}

Lavender oils from ETJA and Crimea most effectively reduced the number of mixed microbiota cells from facial skin at a concentration of $70 \mu \mathrm{L} / \mathrm{cm}^{3}$, although no complete bactericidal activity was observed. The most sensitive to ETJA lavender oil were Gram-positive bacilli, and Gram-negative bacilli were the most sensitive to Crimean lavender oil. On the other hand, neither of the tested oils inhibited the growth of Gram-positive cocci. The tested lavender oils differed in their chemical composition quantitatively and qualitatively; 33 ingredients were identified in ETJA oil, including five compounds not described before (e.g., cyclofenchene and isoborneol); 101 components were identified in Crimean lavender oil, including 37 compounds not described before (e.g., octen-1-ol acetate and linalool formate). Two types of columns of different polarity allowed for better separation and identification of essential oil components such as limonene and eucalyptol. ETJA lavender oil was composed mainly of monoterpenoids (76.7\%) and monoterpenes $(22.7 \%)$, whereas Crimean lavender oil consisted mainly of monoterpenoids (80\%), much less monoterpenes (5.8\%), and some sesquiterpenes (8.0\%; Table 5). Such differences in chemical composition were most likely due to the different geographical origins of the plant material. The analysed lavender oils differed in their bactericidal effect; ETJA lavender oil with higher monoterpenoid content (linalool and linalyl acetate) and monoterpene content (limonene) was characterised by higher efficiency than Crimean lavender oil.

Author Contributions: Conceptualization, M.B., E.N.-B. and T.K.-Ł.; methodology, M.B., E.N.-B. and T.K.-Ł.; formal analysis, M.B., E.N.-B. and T.K.-Ł.; data curation, M.B.; writing-original draft preparation, M.B., E.N.-B. and T.K.-Ł.; writing-review and editing, M.B.; visualization, M.B.; supervision, P.P.W.

Funding: This research received no external funding.

Conflicts of Interest: The authors declare no conflicts of interest.

\section{References}

1. Jabłońska-Trypuć, A.; Farbiszewski, R. Sensory and Basics of Perfumery; MedPharm: Wroclaw, Poland, 2008; pp. 114-115, 121-129.

2. Lazzara, M.V. Aromatherapy. Healing Baths; Bauer-Weltbild Media Sp. z.o.o.: Warszawa, Poland, 2003; pp. 19-29.

3. Góra, J.; Lis, A. The Most Valuable Essential Oils; UMK Publishing: Torun, Poland, 2005; pp. 165-175.

4. Góra, J.; Lis, A. The most valuable oils-Lavender oil. Aromaterapia PTA 1995, 2, 5-11.

5. Glinka, R.; Glinka, M. Cosmetic Recipe with Elements of Cosmetology; MA Publishing: Lodz, Poland, 2008; pp. 70-73. 
6. Janeczko, Z.; Pisulewska, E. Domestic Oil Plants. Occurrence, Cultivation, Chemical Composition, Application; "Know-How" Publishing: Kraków, Poland, 2008; pp. 7-11, 43-47.

7. Da Porto, C.; Decorti, D.; Kikc, I. Flavour compounds of Lavandula angustifolia L. to use in food manufacturing: Comparison of three different extraction methods. Food Chem. 2009, 112, 1072-1078. [CrossRef]

8. Danh, L.T.; Han, L.N.; Triet, N.D.A.; Zhao, J.; Mammucari, R.; Foster, N. Comparison of chemical composition, antioxidant and antimicrobial activity of lavender (Lavandula angustifolia L.) Essential oils extracted by supercritical $\mathrm{CO}_{2}$, hexane and hydrodistillation. Food Bioprocess Technol. 2013, 6, 3481-3489. [CrossRef]

9. Reverchon, E.; Della Porta, G. Supercritical $\mathrm{CO}_{2}$ extraction and fractionation of Lavender essential oil and waxes. J. Agric. Food Chem. 1995, 43, 1654-1658. [CrossRef]

10. Mantovani, A.L.L.; Vieira, G.P.G.; Cunha, W.R.; Groppo, M.; Santos, R.A.; Rodrigues, V.; Magalhăes, L.G.; Crotti, A.E.M. Chemical composition, antischistosomal and cytotoxic effects of the essential oil of Lavandula angustifolia grown in Southeastern Brazil. Rev. Bras. Farmacogn. 2013, 23, 877-884. [CrossRef]

11. Steltenkamp, R.J.; Casazza, W.T. Composition of the essential oil of Lavandin. J. Agric. Food Chem. 1967, 15, 1063-1069. [CrossRef]

12. Dob, T.; Dahmane, D.; Berramdane, T.; Chelghoum, C. Chemical composition of the essential oil of Lavandula dentata L. from Algeria. Int. J. Aromather. 2005, 15, 110-114. [CrossRef]

13. Shellie, R.; Mondello, L.; Marriott, P.; Dugo, G. Characterisation of lavender essential oils by using gas chromatography-mass spectrometry with correlation of linear retention indices and comparison with comprehensive two-dimensional gas chromatography. J. Chromatogr. A. 2002, 970, 225-234. [CrossRef]

14. Cong, Y.; Abulizi, P.; Zhi, L.; Wang, X. Chemical composition of the essential oil of Lavandula angustifolia from Xinjiang, China. Chem. Nat. Compd. 2008, 44, 810-815. [CrossRef]

15. Daferera, D.J.; Ziogas, B.N.; Polissou, M.G. GC-MS analysis of essential oils from some Greek aromatic plants and their fungitoxicity on Penicillium digitatum. J. Agric. Food Chem. 2000, 48, 2576-2581. [CrossRef]

16. Yazdani, E.; Sendi, J.J.; Aliakbar, A.; Senthil-Nathan, S. Effect of Lavandula angustifolia essential oil against lesser mulberry pyralid Glyphodes pyloalis Walker (Lep: Pyralidae) and identification of its major derivatives. Pest. Bioch. Physiol. 2013, 107, 250-257. [CrossRef]

17. Dadalioglu, I.; Evrendilek, G.A. Chemical compositions and antibacterial effects of essential oils of Turkish Oregano (Origanum minutiflorum), Bay Laurel (Laurus nobilis), Spanish Lavender (Lavandula stoechas L.), and Fennel (Foeniculum vulgare) on common foodborne pathogens. J. Agric. Food Chem. 2004, 52, 8255-8260. [CrossRef] [PubMed]

18. Hassiotis, C.N. Chemical compounds and essential oil release through decomposition process from Lavandula stoechas in Mediterranean region. Biochem. Sys. Ecol. 2010, 38, 493-501. [CrossRef]

19. Hanamanthagouda, M.S.; Kakkalameli, S.B.; Naik, P.M.; Nagella, P.; Seetharamareddy, H.R.; Murthy, H.N. Essential oils of Lavandula bipinnata and their antimicrobial activities. Food Chem. 2010, 118, 836-839. [CrossRef]

20. Kulkarni, R.R.; Pawar, P.V.; Joseph, M.P.; Akulwad, A.K.; Sen, A.; Joshi, S.P. Lavandula gibsoni and Plectranthus mollis essential oils: Chemical analysis and insect control activities against Aedes aegypti, Anopheles stephensi and Culex quinquefasciatus. J. Pest. Sci. 2013, 86, 713-718. [CrossRef]

21. Palá-Paúl, J.; Brophy, J.J.; Goldsack, R.J.; Fontaniella, B. Analysis of the volatile components of Lavandula canariensis (L.) Mill., a Canary Islands endemic species, growing in Australia. Biochem. Sys. Ecol. 2004, 32, 55-62. [CrossRef]

22. Zuzarte, M.; Vale-Silva, L.; Gonçalves, M.J.; Cavaleiro, C.; Vaz, S.; Canhoto, J.; Pinto, E.; Salgueiro, L. Antifungal activity of phenolic-rich Lavandula multifida L. essential oil. Eur. J. Clin. Microbiol. Infect. Dis. 2012, 31, 1359-1366. [CrossRef]

23. Białoń, M.; Krzyśko-Łupicka, T.; Pik, A.; Wieczorek, P.P. Chemical composition of herbal macerates and corresponding commercial essential oils and their effect on bacteria Escherichia coli. Molecules 2017, 22, 1887. [CrossRef]

24. Białoń, M.; Krzyśko-Łupicka, T.; Koszałkowska, M.; Wieczorek, P.P. The influence of chemical composition of commercial lemon essential oils on the growth of Candida strains. Mycopathologia 2014, 177, 29-39. [CrossRef]

25. Adaszyńska-Skwirzyńska, M.; Swarcewicz, M. Chemical composition and biological activity of medical lavender. Wiad. Chem. 2014, 68, 11-12. 
26. Król, S.K.; Skalicka-Woźniak, K.; Kandefer-Szerszeń, M.; Stepulak, A. The biological and pharmacological activity of essential oils in the treatment and prevention of infectious diseases. Postepy Higieny Medycyny Doswiadczalnej 2013, 67, 1000-1007.

27. Martini, M.C. Cosmetology and Pharmacology of the Skin; PZWL Publishing: Warszawa, Poland, 2007; pp. 37-44, 52, 105-112, 122.

28. Grzybowski, J.; Zaborowski, P. Theoretical and Practical Basis of Infectology; Institute of Health Protection Problems, Borgis Publishing: Warszawa, Poland, 2007; pp. 34-55.

29. Szewczyk, E.M.; Dudkiewicz, B.; Lisiecki, P.; Różalska, M.; Sobiś-Glinkowska, M.; Szarapińska-Kwaszewska, J. Bacteriological Diagnosis; PWN Publishing: Warszawa, Poland, 2005; pp. 11-159, 205-207, 297-342.

30. Brud, W.; Konopacka-Brud, I. Essential oils as active substances in cosmetics. Herb. Messages 1998, 7/8, 8-10.

31. Jaroszewska, B. Cosmetology; Atena Publishing: Warszawa, Poland, 2004; pp. 93-94.

32. Peters, B.; Kerkhoff, E.; Kuska, S.; Schweig, W.; Wulfhorst, B. Cosmetology; Stam REA Publishing: Warszawa, Poland, 2006; pp. 42-43, 233.

33. Cavanagh, H.M.A.; Wilkinson, J.M. Lavender essential oil: Review. Austr. Infect. Contr. 2005, 10, 35-37. [CrossRef]

34. Sienkiewicz, M.; Denys, P.; Kowalczyk, E. Antibacterial and immunostimulatory effect of essential oils. Int. Rev. Allergol. Clin. Immunol. 2011, 17, 40-44.

35. Boelens, M.H. Chemical and sensory evaluation of Lavandula oils. Perf. Flav. 1995, 20, $23-51$.

36. Adaszyńska, M.; Swarcewicz, M.; Markowska-Szczupak, A. Comparison of chemical composition and antimicrobial activity of Lavender varieties from Poland. Post. Fitoter. 2013, 2, 90-96.

37. Gören, A.C.; Topçu, G.; Bilsel, G.; Bilsel, M.; Aydoğmuş, Z.; Pezzuto, J.M. The chemical constituents and biological activity of essential oil of Lavandula stoechas ssp. stoechas. Zeitschrift Für Naturforschung C 2002, 15, 797-800. [CrossRef] [PubMed]

38. Sabara, D.; Kunicka-Styczyńska, A. Lavender oil-Flavouring or active cosmetic ingredient? Food Chem. Biotechnol. 2009, 73, 37-42.

39. Roller, S.; Ernest, N.; Buckle, J. The antimicrobial activity of high-necrodane and other lavender oils on methicillin-sensitive and -resistant Staphylococcus aureus (MSSA and MRSA). J. Altern. Complement. Med. 2009, 15, 275-279. [CrossRef]

40. Kalemba, D. Antibacterial and antifungal properties of essential oils. Post. Mikrobiol. 1998, 38, $185-203$. [CrossRef]

41. Trytek, M.; Paduch, R.; Fiedurek, J.; Kandefer-Szerszeń, M. Monoterpenes-Old compounds, new applications, and biotechnological methods of their production. Biotechnologia 2007, 76, 135-155.

42. Grabowska, K.; Janeczko, Z. Essential oils with antiviral activity. Aromaterapia PTA 2009, 58, 9-20.

43. Johnson, O.O.; Ayoola, G.A.; Adenipekun, T. Antimicrobial activity and the chemical composition of the volatile oil blend from Allium sativum (Garlic Clove) and Citrus reticulate (Tangerine fruit). Int. J. Pharm. Sci. Drug Res. 2013, 5, 187-193.

Sample Availability: Samples of the compounds are not available from the authors.

(C) 2019 by the authors. Licensee MDPI, Basel, Switzerland. This article is an open access article distributed under the terms and conditions of the Creative Commons Attribution (CC BY) license (http://creativecommons.org/licenses/by/4.0/). 